\title{
The four-level interchange between M4 and M5 motorways at Almondsbury
}

\author{
O. A. KERENSKY \& N. J. DALLARD
}

Mr T. L. G. Deuce, Ministry of Transport

I congratulate the Authors on a paper which is very interesting and informative not only for its bridge design content but also for its comprehensive coverage of traffic figures, quantities, and costs.

90. It has been said that superficially the structure resembles several of the American interchange designs in that a series of discrete cylindrical columns support continuous decks. However, the unique quality of the Almondsbury design is apparent in the form of construction adopted for the bridge decks and columns. It is the first example of the use of this type of column and bridge design has undoubtedly been advanced by the thinking that has gone into the whole of the Almondsbury design.

91. I was closely associated with the design of the Lofthouse Interchange which is the only other full motorway interchange so far built in Britain. I studied the traffic figures which justified a four-level solution at Almondsbury with some degree of envy as preliminary designs for a four-level junction at Lofthouse had to be abandoned in favour of a three-level junction when traffic predictions showed that much of the interchange facility. would be short-circuited by the overall road network in the area. It was with regret that we settled for a three-level junction. I notice that at Almondsbury the 1980 traffic predictions for the SW quadrant, which should have the least traffic, have already been exceeded. Mr Dallard emphasized that this was on a bank holiday; nevertheless, it was a long time after the opening of the bridge. However, I do not think that this detracts from the justification given by the traffic figures to this form of construction.

92. The Paper states that the cloverleaf was rejected because continuous flow would be impossible in two of the loops. Presumably this is a reference to the restrictions caused by weaving on the $\mathrm{N}$-bound carriageway of the M5. Mr Dallard has emphasized that land take and cost.would also have been reasons for its rejection.

93. At first sight it is surprising that concrete encasement has been applied to the outer faces of the outer main girders particularly for the M5 girders where the concrete is not in contact with or continuous with the deck concrete or the concrete on the inner faces.

94. Although risks of staining from the use of Corten steel might arise if the design were currently being prepared, it is apparent from the Paper that the U-frame action and the composite flexural action of the concrete are sufficient in themselves to justify the concrete in its own right and that corrosion protection is a secondary consideration.

95. The $K$ value of 15 adopted for the design of the Hi-load bearings attracts attention when it is related, as in the Paper, to the BS 153 values of 120 for high yield steel and 200 for mild steel. The bearings have been said to be made of high yield steel. In fact a special steel with a Brinell hardness number in the region of 450 was used.

96. Hertz's theoretical work suggests that bearing resistance is proportional to the square of the Brinell number and the $K$ value of 15 is in keeping with this theory. Dr Kerensky may care to comment further on the topic of bearing stresses.

Paper published: Proc. Instn civ. Engrs, 1968, 40 (July) 295-320. 
97. Solid plate open deck joints at Almondsbury were coated with epoxy and impregnated with calcined bauxite to reduce the danger of skidding. These are expensive items and the Ministry of Transport Technical Memorandum BE6 now recommends the use of epoxy mortar nosings for expansion joints wherever possible because they are economical in first cost and likely to have satisfactory maintenancefree lives. Experience of their use to date has been encouraging with any faults being attributable to poor workmanship.

98. Similarly, the split block facings used on the Almondsbury abutments are now generally considered to be an unwarranted expense. Technical Memorandum BE2, issued in October 1966, stipulates that the final exposed concrete shall be either smooth or textured, using formwork of sawn boarding or lined with plastic sheeting. Alternatively, an exposed aggregate finish may be adopted. Exceptions to this general rule have to be considered on their merits. In this context, it is worth noting that textures in the form of grooves or indentations are much less expensive and troublesome than projections.

99. Almondsbury interchange was the subject of a feedback meeting at which the Contractor, the designer and the Ministry were represented. These meetings are reported to those who are interested in highway engineering and the reports have focused on a number of points which could lead to economies in future contracts.

100. At the Almondsbury meeting concern was expressed about the present CEGB policy which seeks to restrict the p.f.a. concession in any particular area to only one firm, and similarly to restrict access rights to p.f.a. stockpiles to only one firm's transport. We in the Ministry are, as a consequence of this, watching for tendencies for the site costs of this material to be excessive.

101. Also at the meeting the use of precast copings for parapets was considered to be an unjustifiable extra expense. Although it is easier to obtain a good standard of finish, there have been numerous instances where a first-class finish has been obtained using in situ concrete throughout. It should be noted that wherever precast copings are used they must be positively fixed to the structure. There was a recent accident resulting from copings being dislodged from a roundabout on to traffic passing underneath.

Mr M. A. Selfe, County Surveyor's Department, Gloucestershire County Council In their admirable and concise Paper the Authors state that the adopted scheme met the requirements of continuous flow capacity and safety. An examination has been made of all the accidents on the M4 near the interchange since its opening in September 1966 . The four sections examined cover $3 \mathrm{~km}$ from the points of merging or diverging of the slip roads and the results are given in Table 3 . The figures indicate

Table 3

\begin{tabular}{l|l|c|c|c|c|c}
\hline \multicolumn{2}{c|}{ M4 } & Killed & $\begin{array}{c}\text { Severe } \\
\text { injury }\end{array}$ & $\begin{array}{c}\text { Slight } \\
\text { injury }\end{array}$ & $\begin{array}{c}\text { Total no. } \\
\text { of } \\
\text { reported } \\
\text { accidents* }\end{array}$ & $\begin{array}{c}\text { Traffic } \\
\text { estimate } \\
\text { r.c.p.u. } \\
1968\end{array}$ \\
\hline West-bound & $\cdot\left\{\frac{\text { Approach }}{\text { Exit }}\right.$ & - & 4 & 11 & 8 & 9000 \\
\hline East-bound & - & - & - & - & 2 & 15000 \\
\hline Exproach & 2 & 4 & 1 & 11 & 15000 \\
\hline
\end{tabular}

- $9 / 9 / 66-30 / 9 / 68$. 
that accidents on this interchange are more frequent on approaches than on exits. On the approaches the driver has to make decisions, but once past the junction he is certain of his course of action.

103. Further study of the approach accidents shows that the west-bound incidents are diverse in character and have no discernible pattern; $12 \frac{1}{2} \%$ occurred at night. Of the east-bound accidents $82 \%$ involved end collision, with a light vehicle running into the back of a lorry, and $73 \%$ occurred at night.

104. The west-bound approach is straight and falls towards the point of divergence of the slip road at a gradient of $1 \%$. On the east-bound approach, traffic proceeds on a two-lane carriageway from the Severn Bridge over fairly level alignments to a point $2.1 \mathrm{~km}$ from the interchange. There is then a $4 \%$ ascending gradient for $1.2 \mathrm{~km}$. A third lane is provided from the start of this gradient to the interchange. The profile continues to rise over a vertical curve to a point $225 \mathrm{~m}$ from the divergence of the M4 and M5, rising over the vertical curve and then falling away slowly into the interchange. Visibility to the junction is approximately $370 \mathrm{~m}$. The $4 \%$ gradient is mainly on a straight, but near its top there is a right-hand curve of $1940 \mathrm{~m}$ radius, leading to the interchange.

105. Advance direction signs begin at the foot of the gradient and drivers are, therefore, aware of the need to negotiate a junction from that point. Visibility to the gantry sign, which is $5.4 \mathrm{~m}$ high above the intersection, is $460 \mathrm{~m}$.

106. The pattern and severity of accidents on the east-bound approach are such that they require further study. The accident record forms show that the majority occur towards the top of the $4 \%$ gradient; only three occurred in the region within $600 \mathrm{~m}$ of the junction. Two layout factors are thought to be contributing to this situation. Firstly, the $4 \%$ gradient is causing greatly differing speeds between heavy and light vehicles on the gradient and beyond to the intersection: $85 \%$ of cars travel at $64 \mathrm{mile} / \mathrm{h}$ at the bottom of the gradient and slow down to just over $50 \mathrm{mile} / \mathrm{h}$ on it. Similar figures for heavy goods vehicles are $40 \mathrm{mile} / \mathrm{h}$ and $16 \mathrm{mile} / \mathrm{h}$. Secondly, the inability of drivers to see the point of divergence of the two motorways causes movement to be made uncertainly.

107. The following signs have been erected as remedial measures:

(a) advance direction signs;

(b) warning signs for heavy lorries on the gradient;

(c) junction count-down signs.

It is not possible to report whether these measures have made any improvement but I think it unlikely. The Ministry of Transport is also considering a proposal to illuminate this section of motorway, bearing in mind that $73 \%$ of the accidents were at night.

108. The topographical difficulties in the site are recognized. Even so, there is, clearly, a deficiency in the layout. Can the Authors say whether this problem was anticipated and, if so, whether the following three possible changes in design were considered:

(a) an alteration in horizontal alignment to give a straight approach as on the west-bound side of the intersection;

(b) the lowering of the approach profile to increase drivers' visibility of the point of divergence of the motorways;

(c) the provision of separated carriageways for the M4 and M5 at least to a point well beyond the crest and preferably down the gradient (this latter work can still be done).

The point of my contribution is to emphasize that a completely safe free flow intersection must be integrated with the design of the approaches, where accident potential is high.

109. I would ask the Authors what their personal solution would be to the problem which I believe will be with us for some time. 


\section{Mr P. F. Foice, Chief Superintendent of Police, Cheltenham}

Without having the M5 motorway in use it is difficult to decide what will happen to the traffic when the four-level intersection is fully operational. There are two problems. Mr Selfe described the first, and I shall approach it from a policeman's point of view. The rise in gradient to the interchange gives motorists approaching it a very limited view of the four-level intersection. On the nearside of the gradient is a crawler line for slow-moving vehicles, and near the crest, just before the interchange, the slip road for the M5 bears off to the right. At the slip road, slow-moving vehicles appear to be in the centre of the road. I think this is why some of the accidents occur. One cannot cater for all motorists: some of the accidents are caused by the few motorists who do not read road signs.

111. A further hazard occurs when travelling from the Severn Bridge eastwards and taking the M5 slip road, that is the top level of the intersection bearing right and travelling south. On leaving the interchange there is an advance direction sign indicating the slip road coming in from the left for traffic travelling westwards on the M4 and going south on the M5. There is a red bar across the indication sign before the junction and two total prohibition signs on the mouth of the slip road, yet some motorists still turn $300^{\circ}$ left against the flow of traffic.

112. Since the opening of the motorway four vehicles have caught fire on the top level of the interchange. On each occasion the fire service sent an appliance to every level, because of the possible spillage of fuel from one level to another. The four fire accidents so far have all been controlled fairly quickly and have not caused more than one level to be closed, but imagine that a petrol tanker containing 20000 gallons were involved in an accident. This might mean closing all the four levels together. The side roads will never take the volume of traffic that a motorway will take, so there is a fire problem on a bridge.

\section{Mr P. E. Lindesay, Costain (Civil Engineering) Ltd}

Having been closely associated and considerably taxed on site with problems of presetting columns, and of presetting the birdcage scaffolding and temporary works to levels such that we should achieve as nearly as possible the final profile after stripping and after all settlements had taken place, I should be interested to hear whether Dr Kerensky can supply details of final settlements and say whether or not the theory applied to the fore-shortening of columns and bearings has proved correct.

114. The Paper refers to the use of a monorail for concreting the two upper decks of the M5 and the principal slip roads. Although the use of a monorail is by no means unique, on this occasion it involved the use of a moving bridge. The rails were set $36 \mathrm{ft}$ apart and a moving bridge travelled on them to give a closed circuit at all times, so that the main rail supports of the monorail were positioned only once for the entire deck. This covered all the necessary pours and sequences of pours.

115. At the $36 \mathrm{ft}$ span the bridge, which the designers assured us would settle very little, sagged almost a foot under the weight of a loaded unit and a trailer. There was danger of striking the top reinforcement, and so a small screw jack was provided which raised the bridge up to clear the reinforcement, the jack being lowered and the whole bridge moved forward and rejacked as the pour progressed. With this particular use of the monorail an output in excess of $30 \mathrm{cu} . \mathrm{yd} / \mathrm{h}$ was achieved using three units consisting of a motor and trailer unit, each having a $3 \mathrm{cu}$. yd capacity for each complete cycle.

\section{Mr W. A. Eyre, Freeman Fox and Partners}

The Ministry of Transport 'Pink Book' specification deals most effectively, in the case of cohesive soils, with soils wetter than their laboratory optimum moisture content. The materials encountered at Almondsbury presented the problem of how 

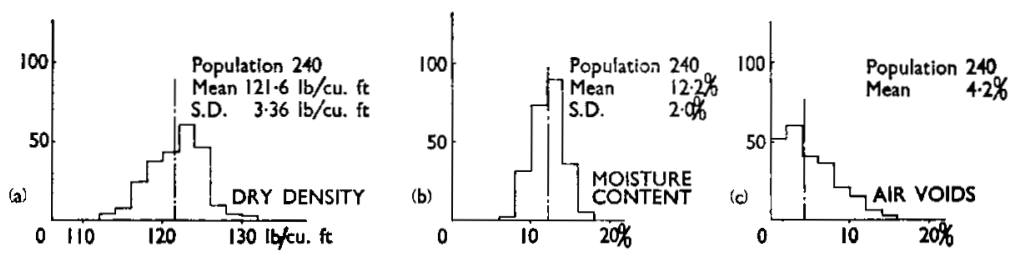

Fig. 18. Dry density, moisture content and air content

to deal with soils considerably drier than optimum which had been protected from weathering by the presence of several bands of limestone in the upper layers.

117. On the surface was a brown weathered lias clay containing limestone bands each a few inches thick. The quality of this material verged on the unsuitable at times at the specified moisture content of plastic limit $+4 \%$, but these stone bands helped to stabilize material in this condition when placed in embankment.

118. Underlying the weathered lias, the rhaetic shales were about $12 \mathrm{ft}$ thick and contained three or four bands of hard limestone each 4-6 in. thick. This soil had a mean moisture content of $13 \%$ in relation to a plastic limit in excess of $20 \%$, but when used as filling it did not prove particularly difficult to attain the specified air voids at a mean dry density of about $109 \mathrm{lb} / \mathrm{cu}$. ft.

119. Underlying the rhaetic shales was the Keuper marl, the uppermost layer of which, known as tea green marl, had to be blasted and compacted to the rock specification. This material was spread and tracked by a heavy bulldozer and received eight passes of a 15 ton grid roller.

120. Very little red Keuper marl was excavated from within the Almondsbury site but a considerable part of the $400000 \mathrm{cu}$. yd of material imported from the adjoining Severn Bridge Approach Contract consisted of this material. It too came from a very deep cutting, well protected from weathering, and although it crushed to a fine grading when placing and compacting, it was difficult to achieve the specified air voids, particularly in the $5 \%$ zone.

121. It proved impossible to compact this material to the air voids specification and a minimum dry density of $117 \mathrm{lb} / \mathrm{cu}$. ft was accepted. Fig. 18 shows histograms indicating the range of dry density, moisture content and air voids with means of $122 \mathrm{lb} / \mathrm{cu}$. ft at $12 \%$ moisture content with $4 \%$ air voids, although the latter ranged up to $14 \%$. As might be expected from an overconsolidated clay, there was some swelling and loss of density over the winter months and the tops of the shale and marl embankments were recompacted prior to the start of paving works, with an 8 ton ABG vibrating roller. The paving has not yet been completed on part of the red marl embankment. It will be interesting to see what the equilibrium moisture content of these materials has become when the balance of the paving is carried out in the next phase of the work in another 18 months' time, when the M5 is continued north of Almondsbury. It is possible that they will not have wetted-up appreciably.

122. Experience with these dry materials at Almondsbury led to the inclusion of a method specification for dealing with identical marls on the next length of the motorway, three miles to the south, which is at present in hand. This is applied to marls at a moisture content lower than $5 \%$ below their plastic limit and requires sixteen passes of a 13 ton grid roller in the $10 \%$ zone and 24 passes in the $5 \%$ air voids region, after spreading and tracking by heavy dozer. Incidentally, the increase in density for additional passes in excess of the conventional eight has been found to be substantial.

123. In a similar fashion a method specification for the compaction of fly ash developed out of experience with this material at Almondsbury. This was an exlagoon material from Portishead Power Station which was known to be variable, with 

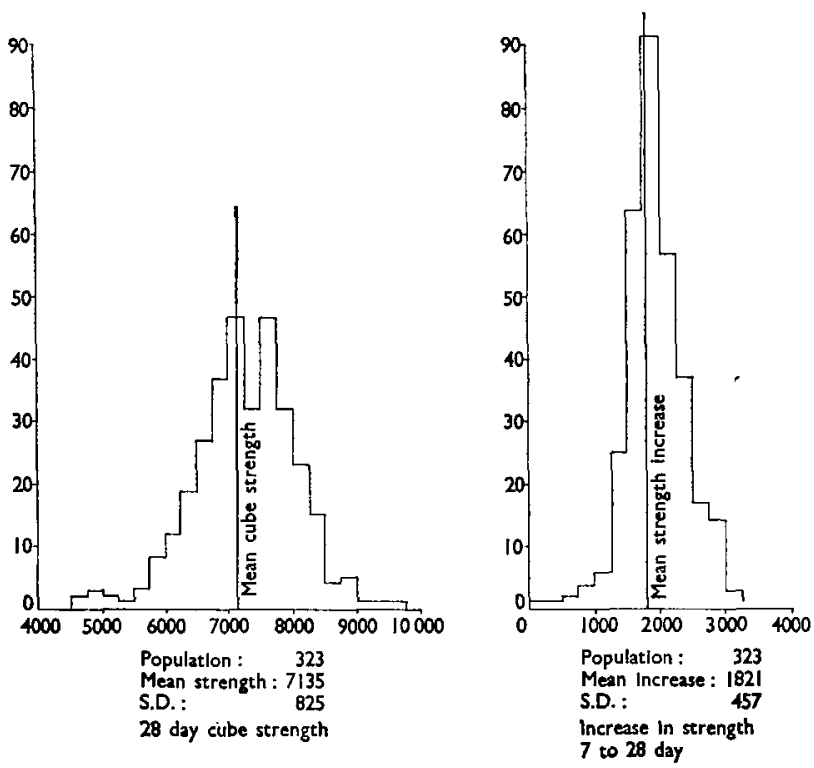

Fig. 19. Results of cube testing

optimum qualities ranging from a dry density of $63 \mathrm{lb} / \mathrm{cu}$. $\mathrm{ft}$ at a moisture content of $36 \%$ to $83 \mathrm{lb} / \mathrm{cu}$. ft at a moisture content of $22 \%$. The air voids specification could not be applied, but a technique was developed of comparing the dry density found from a sand replacement test with a Proctor test carried out in the field at the naturally occurring moisture content: $100 \%$ of this Proctor standard was readily achieved with eight passes of a towed vibrating roller, whilst subsequent consolidation with time has proved to be negligible.

124. On current work, this standard has become the criterion for a method specification for compacting this material.

\section{Mr M. G. Lewis, Freeman Fox and Partners}

The use of readymix concrete on this structure is noteworthy. Many engineers would not like to use it on a structure of this nature because it removes the control of the product from the Contractor's and the Engineer's site staff. It was necessary to use readymix concrete in this case because of the complex layout of the structure which made continuity of concreting a difficult problem for the Contractor. When the steelwork was being erected for the composite decks it was not possible to do any deck concreting on any of the other levels. It was also necessary to carry out some quite large pours, the largest being of the order of $450 \mathrm{cu}$. yd, and rates of pour of 30-50 $\mathrm{cu} . \mathrm{yd} / \mathrm{h}$ were required.

126. Having accepted readymix concrete, a check was carried out on the various suppliers in the area. It would have been useful at the time of the Contract if the British Readymixed Concrete Association's Authorization Scheme for readymixed concrete plants had been established. The Association intends to inspect and grade plants and if it is able to enforce the standard that it requires this will be very useful in writing contract documents since it will be possible to specify the grade of plant 


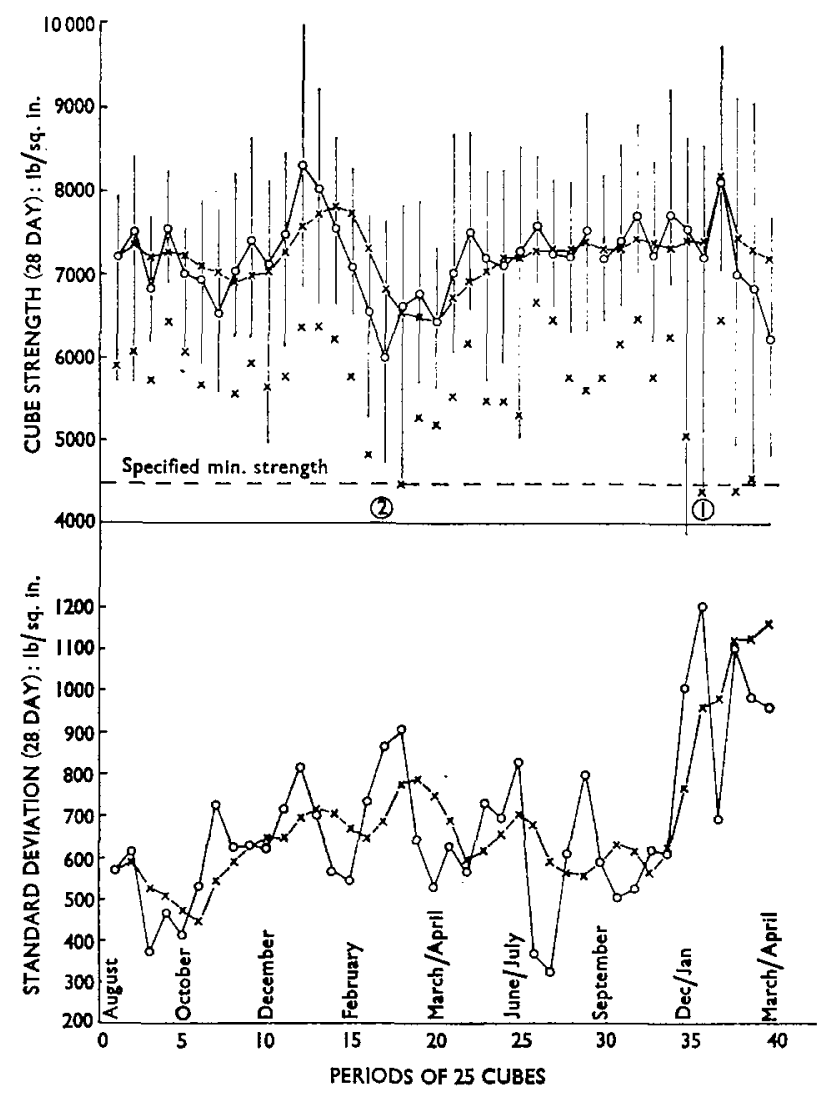

Fig. 20. Cube strengths

required. This scheme would also make tendering fairer for readymixed concrete companies.

127. Once the plant has been approved it is best to check the concrete on site, with only occasional checks on the batching equipment and aggregate gradings. Compaction factor tests were carried out on $80 \%$ of the concrete batches. Cubes were also taken from all important pours at the rate of a set of $6 \mathrm{cubes} / 50 \mathrm{cu}$. yd of concrete.

128. Fig. 19 shows the results of cube testing on the $4500 \mathrm{lb} / \mathrm{sq}$. in. concrete used in the foundations, beams and deck slabs. Fig. 19 also shows the gain in strength between 7 day and 28 day cubes. These results illustrate the strengths that are possible with lean mixes using modern cement and limestone aggregates. The aggregate:cement ratio was approximately 5.9 and the water:cement ratio 0.5 . The attainment of the specified cube strength was not very difficult with the ordinary Portland cement which in actual fact complied with the minimum requirements of rapid-hardening cement. The main problem was the attainment of good workability with the crushed rock aggregate and zone 4 sand. The excellent finish that was produced was definitely a feature of the very good gap-graded mix designed by the 
Contractor. Admixtures were only used for the concrete in a very limited number of locations where the additional workability was required. More extensive use of admixtures may well become more common in areas where lean concrete mixes are possible, and the new British Standard for admixtures which is about to be published will be of assistance in this matter.

129. Fig. 20 is the graph of cube strengths and standard deviation which was kept up to date as the work progressed. It is interesting to note that the mean strength varied seasonally. This is a point which must be watched when very lean mixes are being used. In the case of the Almondsbury Contract extra cement had to be ordered on two occasions to correct the downward trend in the mean strengths. The fairly high standard deviation was partly due to the seasonal variation in the cement quality and the standard deviation figure of $825 \mathrm{lb} / \mathrm{sq}$. in. shown on Fig. 19 has not been corrected to allow for the additional cement content which had to be ordered.

Mr P. J. Clark, Imperial College of Science and Technology (formerly Freeman Fox and Partners)

Dr Kerensky has pointed out that the structure is articulated so that each level is free to move in its own plane, supported on rocker columns. This articulation, which involved the development of a spherical bearing carrying a load of 3200 tons on a bearing area about the size of an ashtray, was adopted only after careful consideration of the alternatives. The combination of stocky columns and a relatively slender deck slab, and the uncertain movements to be introduced by temperature, shrinkage and erection meant that the support moments induced in a highly redundant structure would have been large and difficult to predict. Any form of moment connexion between columns and deck structure debits both the columns and the connexions with heavy moments under particular load conditions, without any compensating economy elsewhere. The decision to build the structure on stilts thus led to certainty in the analysis, economy in the structure, and also simplified construction.

131. It was from consideration of the articulation that the idea of a concrete filled tube first came. Part of the problem is that the heavily loaded columns are relatively short. One has perhaps 10,12 or $14 \mathrm{ft}$ of column and an enormous load to be transferred from one end to the other, so that a large part of the cost of the column will be in the bearings. If a hollow tube is selected, the central point load has to be distributed out to the skin, and then almost immediately collected again and transmitted on through another central point. It seemed that if we could solve this by using a column which operated in exactly the same way as a motorcar jack, except that we would use concrete instead of fluid, we should have a very good column.

132. The initial design was an attempt to produce such a column extremely cheaply and without the close machining and careful construction mentioned by Dr Kerensky. The end bearing was to be a loose fit inside the steel pipe, bearing on the concrete and depending on the development of hoop tension in the pipe to restrain the highly stressed concrete below the bearing.

133. Subsequent testing has shown that the concrete below the bearing may compress by $\frac{1}{4}$ to $\frac{1}{2}$ in. before this, restraint is obtained, and in this structure this was unacceptable. However, I feel that there is a place for columns with some such simple bearing detail, in structures less sensitive to bearing settlement. The elevated urban motorways now being built, subject to temperature movement and having complex geometries, might be suitable candidates. In this application columns would be very much smaller, and the bearing 'settlements' correspondingly lower.

134. A comment on a matter of detail: at an early stage in its life, the design of the Hi-load pad was as shown in Fig. 21. The curve was chamfered off beyond a 6 in. dia. bearing area. The chamfer was fine enough to retain the triaxial strength needed to resist the high bearing pressure, but sharp enough to prevent severe eccentric loading 


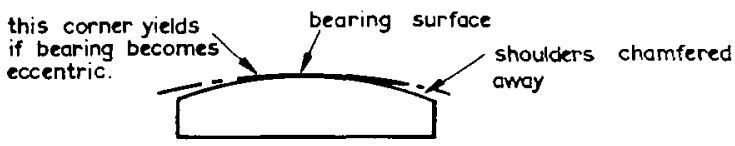

Fig. 21. Hi-load pad

on the column if the mating bearings were slightly out of true. The detail implied local yielding of the Hi-load steel, and perhaps this is why it was finally rejected.

135. The requirements of the anti-crack formula in force at the time did not help the design, and as Dr Kerensky has indicated, present rules would lead to much lower congestion of bars and shear connectors. In attempting to meet the requirements of the formula, a large area of anti-crack steel had to be provided, and this in turn required the provision of a large number of shear connectors to bring it into the section. Uncertainty as to the width of deck slab acting, however, limited the amount of reinforcement which could be taken as acting in the girder section.

136. At the M4 level so much reinforcement had to be put into the concrete of the beams that the tension flange became too small for erection, and had to be stayed temporarily. I think that we ought to look very carefully at our anti-crack requirements to see whether we are still putting too much of this steel in.

137. Regarding the more general application of this type of construction, spine beams can be most usefully used to extend the range of concrete construction. Where overall construction depth is governed by a limited number of heavily loaded members, these can conveniently be designed with steel spines, thus allowing the depth of the structure overall to be kept down, with consequent economy.

\section{Dr J. C. Chapman, Imperial College of Science and Technology}

The investigation into the tubular columns which was necessitated by this design formed the starting point of a more general programme of research. I should like to mention the stage that this research has reached and also its application to this design.

139. The approach that is being used is to take the stress/strain curve for steel and concrete and use a computer to calculate the failure load of columns under eccentric loading. Programs are available from a number of places for treating columns in this way and satisfactory agreement is found with experiments for tubular columns and encased columns. By comparison with calculation it can be inferred that columns with a length: diameter ratio of more than about 10 are not significantly affected by triaxial effect. Even for stocky columns a large hoop effect would not be expected if the eccentricity were large.

140. Computer programs have been used to compute design tables for concretefilled tubes, and these are now in course of production. The same programs have also been used to write design formulae which we think may well be incorporated in Codes of Practice B116 and 117. The programs have been used to calculate failure loads for columns used at Almondsbury. If we ignore the columns with $\frac{3}{8}$ in. wall thickness, where the wall thickness was determined on the grounds of minimum practical thickness rather than on purely structural grounds, we find a range of load factors slightly greater than the minimum values at which the Authors were aiming.

141. We are now proceeding to look at triaxial effects. These concern only stocky columns where the eccentricity is small, and even then the triaxial effect comes into play only when the strain is rather large. When the strain is small, within the elastic range of steel and the reasonably linear part of the concrete stress/strain curve, Poisson's ratio for concrete is less than for steel, so the concrete is restraining the steel from expansion and the triaxial effect does not operate.

142. For this reason one would question the logic of equation (3) (which was not 
used in the design) as to whether it is suitable for calculating first yield load. It includes a term for the hoop tension in the steel and the restraining effect on the concrete $(t / R) f_{\mathrm{5}}$. I would say that the factor for calculating first yield load, though it is appropriate to some degree in equation (2), is perhaps not appropriate to the degree suggested.

143. We have available a fair number of tests on short columns where the longitudinal and hoop strains have been measured. These are being analysed in the postelastic range and the longitudinal stresses can be calculated from the strain increments. The transfer of load which has to take place in the steel tube is being traced through step by step. The indications are that failures in very short tubular columns occur by shear before there has been a full transfer of load from the longitudinal direction to the hoop direction in the steel tube.

144. In $\S 33$ the Authors say that shear reinforcement was provided in the concrete encasement to cater for the vertical shear forces in the composite beam. I should like to ask how the shear force was apportioned between the concrete encasement and the steel web of the beam.

\section{Professor A. J. S. Pippard, Past President}

As I understand it, the bearing for each column is formed by a spherical pad resting on a hardened steel plate. A similar point in design on a much smaller scale occurred during the last war and was solved by drilling a circular hole through the lower plate and allowing the spherical head to set itself upon the perimeter of the hole. Experiment showed that good centering with effective line contact was established and the stress was far more evenly distributed than in the Brinell type of indentation when the spherical surface is in contact with a flat surface.

\section{Mr M. F. Palmer, Joseph Westwood \& Co. Ltd}

Hi-load steel is very ductile, and the area in contact between the two surfaces (which can be determined since after testing a shine appears on the surface) is the area found by stressing the steel to about 130 ton/sq. in. For the 3200 ton bearing, the area in contact would be about 25 sq. in.

147. One speaker mentioned the severe cut-off away from the spherical surface. I do not remember it, but that would have been a bad feature, because one has to have a certain backing to the area which is under load to enable it to sustain the load. In other words, at the end of a roller or at the end of a plate the amount of pressure which the roller or plate can take at that point is much lower because it has no backing. The same thing would apply if one cut the plate away at the edge of the contact surface. One always needs a backing for it. This also applies to the thickness of the slab. It needs a certain thickness in relation to its diameter.

148. The steel compresses under load, but up to the figure of $130 \mathrm{ton} / \mathrm{sq}$. in. it always recovers. Thus, when the bearing has been tested the profile is still correct. In rotation the material moves contact with the line of the load and comes back to its original position when the load has passed.

\section{Dr Kerensky and Mr Dallard}

We thank Mr Deuce for his contribution and complimentary remarks. He commented on the 1980 traffic prediction for the SW quadrant being exceeded in 1967. We are sure that this is of no significance because it happened only 8 months after the interchange was opened, before all traffic movements were provided for, and during the first bank holiday after the winter when the interchange and Severn Bridge were a novelty.

150. Regarding the rejection of the cloverleaf, the reason was simply lack of traffic capacity on two of the loops and higher accident potential than the four-level scheme. 
151. If the outer concrete facing on the outer beams were omitted, maintenance painting would be required and this we sought to avoid. At that time Corten types of steel were hardly available and very expensive and in any case would not be appropriate from the point of view of appearance.

152. The $K$ value of 15 that was used in the design of Hi-load (not high yield) bearings was agreed with the makers and is conservative: $7 \frac{1}{2}$ could have been used if we had known then what we know now, but these bearings were the first of their kind and we were naturally conservative. In any case, if the difference between the radii of the surfaces in contact is too small there is a danger of seizure under load. One of the earlier experimental bearings, in fact, seized and the difference between the radii was subsequently increased. Rigidity of the two bearing elements is another very important factor in the design of these bearings.

153. Epoxy nosings were on trial at the time the Almondsbury joints were being constructed. In our opinion they are still on trial, as none have been in use for a sufficiently long time to be certain that they will not deteriorate under heavy pounding. We think that they may do so and would not like to use them for a heavily trafficked skew joint, even today. In any case half the joints were toothed and had to be made of steel or cast iron; properly fixed, they should be trouble free for a very long time. The only reason for specifying an anti-skidding treatment was that some of the toothed plates had to be rather wide because of the skew. The treatment is not really essential.

154. With regard to the artificial concrete facings, the lower abutments are very long and there was the problem of appearance of a large exposed concrete area. The Architect, Mr R. E. Slater, suggested split block facing to enhance this and to add warmth to the structure. This, perhaps, was the only aesthetic extravagance conceded to him. It is admitted that some sort of pattern of formwork would be used today, instead of the facings. This would save costs at the expense of appearance.

155. The case of parapet copings is different. A sealing of the tops of the walls (containing steel girders) and an overhang to keep the water off the fascia walls were considered desirable. Also the complex camber and curvature requirements made the achievement of a good alignment of a cast in situ parapet very doubtful and the precast copings were provided to hide the expected irregularities. In the event, the Contractor succeeded in producing very good cast in situ parapets, but in our experience this could not have been relied upon. Even so careful setting of the copings has further improved the alignment. The copings are well anchored to the concrete and their dislodgement is most unlikely. On the other hand they are replaceable in case of damage from vehicle impact or other causes. We should like to compliment the Contractor on the standard of workmanship, and particularly on the concrete finishes which are exceptionally good.

156. Mr Deuce asked us to comment on the CEGB's practice of restricting the retailing of pulverized fuel ash to one firm. We believe that lack of competition may well force the price up unless it is controlled by the supplier.

157. Mr Selfe dealt with accidents, and we thank him for going to so much trouble. Our reply to him also covers some points made by Superintendent Foice.

158. A change in the design of the horizontal alignment to give a straight approach on the east-bound carriageway of the M4 was not considered necessary and we do not think it is necessary now. That curve has a very large radius of $6400 \mathrm{ft}$. It does not in theory require superelevation and would, to the average motorist, appear to be straight.

159. His second point was whether we had considered lowering the profile of M4 in order to increase the visibility of drivers. However, the visibility is very good there; in fact, about $200 \mathrm{ft}$ more than the minimum visibility required by the Ministry of Transport. Lowering the profile would have caused difficulties: there were about $30 \mathrm{ft}$ of excavation at the $\mathrm{A} 38$, in very hard rock, and if we had gone any deeper the cost would have risen appreciably. Also, the difficulties in maintaining traffic 
travelling along the A38 - a very busy road - would have been increased, and we should have got into trouble with houses alongside the road.

160. Mr Selfe's third point was about the provision of separate carriageways for the M4 and the M5 at least to a point beyond the crest and down the gradient. We presume that he means separate M4 and the M5 slip road earlier than at present. This would increase the visibility, but we wonder whether this is really what needs remedying. Mr Selfe has said that the majority of accidents have occurred on the east-bound approach of M4 towards the top of the $4 \%$ gradient. Nevertheless, the accident rate on this stretch is about the same as that on similarly aligned parts of the M1-the Road Research Laboratory has recently written a note about this. ${ }^{10}$ Furthermore, the accident rate on the same stretch is less than the national average for motorways. Therefore, we doubt whether the Almondsbury Interchange has any additional effect on accidents, because we should expect accidents on any ordinary length of motorway with a $4 \%$ gradient and a crawler lane and tapers-the crawler lane must end somewhere - to be similar to or even worse than in this particular case.

161. We would agree with $\mathrm{Mr}$ Selfe that further study of this problem is required. We suggest that there could be some more experimenting with temporary signs and road markings; and lighting would undoubtedly help. However, almost certainly there are many other situations where the money could be better spent.

162. An interesting point was made by Superintendent Foice about the possible consequences of vehicles catching fire on any of the bridges. It is almost inconceivable that two major motorways could be closed for any great length of time because of a vehicle on fire. Before a long closure is contemplated the cost of the stoppage to the users, i.e. to the nation, should be worked out. The $3400 \mathrm{ft}$ long four-lane toll bridge across Auckland Harbour in New Zealand, which is operated as a commercial venture, is equipped with telephones, fire fighting appliances and salvage vehicles at the ready, and all accidents are very quickly dealt with.

163. Stand-by emergency services located at Severn Bridge Toll Compound would probably be equally effective in the case of Almondsbury. The danger of fuel or oil spilling from one deck to the other is almost non-existent because all decks are fully contained between solid parapets.

164. Mr Lindesay wondered whether the various columns were correctly setthey certainly are to the keenest eye and that is all that matters. The relative settlements of the various foundations have been, to date, somewhat less than allowed for in the design and the final appearance of the soffits and of the parapet girders is excellent. He mentioned excessive deflexions of the monorail bridge. This, of course, was a piece of plant designed by the makers and not by us.

165. Mr Eyre's knowledgeable comments on compacting dry Keuper marl and fly ash were valuable in that they demonstrated the need for sound engineering judgement when theoretical specifications are impracticable.

166. Mr Lewis's remarks on the use of readymix concrete were interesting and useful. We see no reason against the use of this material provided that the Engineer carries out control testing in the way described and the supplier is willing to co-operate.

167. Mr Clark added some further details and useful explanations of the problems encountered and overcome during the planning stage. We agree that concrete filled tubes with simple rotational bearings at each end can be very helpful for elevated motorways, but believe that they should be sealed at top and bottom to avoid damage by corrosion and freezing. If the concrete got saturated with water and then froze the stresses in the steel tube could reach yield, if not worse. We agree with $\mathbf{M r}$ Palmer's comments concerning the bearing slabs.

168. During the last few years, Dr Chapman has been very much involved in the development of concrete filled columns and, thanks to his work, our knowledge of their behaviour is now appreciably greater. Equation (3) need not be considered any further; it was developed for convenience for the particular case only. It is, however, gratifying to learn that the columns designed by somewhat empirical 
methods have now been shown to be adequate in all respects. In $\S 144 \mathrm{Dr}$ Chapman has put his finger on an unsolvable problem, or at any rate on one we could not solve properly, and we have therefore provided belt and braces. The steel webs were designed to resist all vertical shears. During construction the deck slab props were released before the encasements were cast, so that the entire weight of the slab was, in fact, carried by the steel girders. The vertical and inclined reinforcement in the inner faces of the encasement was designed to resist all the subsequently imposed shears and also the $U$ frame action. The purpose of this was to prevent shear cracks, but the reinforcement was in any case fairly nominal. The composite shear strength of the girders is undoubtedly on the safe side.

169. We doubt if Professor Pippard's annular spherical bearing could deal with the loads in question. Furthermore, the columns rotate appreciably while the longitudinal displacements can be as much as 3 in. and therefore the bearings must allow a rolling movement, which is not possible with the annular contact. The surfaces in contact in the Hi-load bearings are, of course, both spherical and of slightly different radii.

\section{Reference}

10. RRL. The effect of gradient and curvature on accidents on the LondonBirmingham motorway. Road Research Laboratory, Note LN/691/JAH JGW, 1969. 